\title{
Infrared spectroscopy as the method for evaluating technological properties of minerals and their behavior in technological processes
}

\author{
Ihor Kholoshyn ${ }^{1}$, Natalia Panteleeva ${ }^{1, *}$, Oleksandr Trunin $^{2}$, Liudmyla Burman ${ }^{1}$, and Olga Kalinichenko ${ }^{1}$ \\ ${ }^{1}$ Kryvyi Rih State Pedagogical University, 54 Gagarina Ave., Kryvyi Rih, 50086, Ukraine \\ ${ }^{2}$ Kryvyi Rih National University, 11 Vitalii Matusevych Str., 50027, Ukraine
}

\begin{abstract}
Infrared spectroscopy (IR) is a highly effective method for the analysis of minerals, rocks and ores, capable of solving a whole range of problems when choosing innovative solutions for the technological processing of various types of mineral raw materials. The article considers the main directions of using the infrared spectroscopy method in assessing the technological properties of minerals and their behavior in technological processes: evaluation of the grade (quality) of mineral raw materials; analysis of the behavior of minerals in the technological process with prediction of their technological properties; analysis of changes in the structure and properties of minerals in technological processes; operational analysis of mineral substances at various stages of technological processing. The article illustrates all aspects of the use of infrared spectroscopy at various stages of studying the material composition of mineral raw materials in its enrichment assessment by specific examples of solving problems arising from the technological redistribution of various types of ore and non-metallic minerals.
\end{abstract}

\section{Introduction}

The modern stage of mineral processing is characterized by the involvement of increasingly poorer and more difficult-to-concentrate ores in the technological process. In this regard, there is a need for deeper study of their material composition at the level of recent advances in the field of crystal chemistry and crystal physics of minerals with the involvement of a wide range of the latest physical and chemical methods of analysis.

Infrared spectroscopy (IR spectroscopy) has been widely used in recent years in the practice of geological exploration. First of all, this is due to the high resolution of the method, its quickness, versatility and economy. The advantages of IR spectroscopy are most fully shown when studying the crystal chemical features of minerals such as polymorphism, isomorphism, coordination, and the degree of deformation of structural polyhedra. Considering the fact that these attributes are most widely demonstrated in the technological properties of minerals [1], it can be assumed that this method must take its rightful place in a wide arsenal of physical and chemical methods of analysis used for assessing the behavior of minerals at different stages of technological processing of ores of various types of minerals.

\section{Publication overview}

Nowadays the literature contains quite a few examples of the use of infrared spectroscopy in studies of various types of mineral raw materials in order to increase the efficiency of their technological processing. This research currently develops in two directions: geological-mineralogical and technological. Representatives of the former direction (V. Farmer [2], T. Shishelova [4], B. Pirogov [1, 6, 7, 9], A. Ivanov, J. Kloprogge, D. Kamalova [18], E. C. Hecker, A. Remizov [14], R. Skochilov [18], I. Suvorova, N. Batyrshin, V. Stolpovskaya [18], A. Fishman [18], A. Smith [20], R. Frost [26-28], E. Malinowski [30], and the others) reveal signs that determine technological properties of rocks and ores when using infrared spectroscopy to diagnose qualitative and quantitative phase analysis of them, and establishing the crystalchemical features of minerals. The technology research (Yu. Batura [10], B. Rivard, A. Jones, J. Miller [11], R. Clark [19], A. Guatame-Garcia [24], M. Buxton, R. Bedell [24], J. Kellar, R. Lima, P. Brandao, E. Giesekke, I. V. Solnyshkin, V. Chanturia [16, 22], I. Plaksin [25], etc.) are mainly based on the study of surface phenomena using infrared spectroscopy when fixing flotation reagents to minerals, as well as changing their properties under various external influences (thermal, radiation, ultrasound, etc.).

\footnotetext{
* Corresponding author: panteleeva4y@gmail.com
} 
The aim of the article is to analyze and generalize the available published data of the IR spectroscopy method in assessing the technological properties of minerals and their behavior in technological processes of ore processing.

\section{Methods}

The results of the author researches served as the real material of the article, the analysis of a number of the analogous works of the other authors was also presented. The IR-spectra study of minerals, rocks and the enrichment's products was made on the two-rays spectrophotometer Specord of "Carl Zeiss, Jena" firm (Germany) by the method of paste in the refined petrolatum oil. The intensity of the absorption's stripes was measured, according to the method of the basic line. The hardness of minerals was defined by the method of pressing on the PMT-3M hardness micrometer, but the dielectric penetration - by the sensor of Petrzhyk. The content of the elements in minerals and products of the enrichment was determined by the method of the chemical analysis.

\section{Results}

Analyzing the information available today, we can say that infrared spectroscopy can be widely used at various stages of studying the material composition of mineral raw materials while assessing its enrichment; and it can solve various tasks of technological ore processing. Let us consider in detail the main ones.

\subsection{Assessment of grade (quality) of mineral raw materials}

One of the main characteristics of mineral raw materials is a combination of properties that determine compliance with its purpose. The separation of minerals into varieties plays a leading role in assessing the level of its quality.

IR spectroscopy is one of the most effective physical methods for assessing the grade of mined non-metallic mineral raw materials. Thus, studies of phlogopites $\left.\left(\begin{array}{llll}\mathrm{K} \mathrm{Mg}_{3} & {[\mathrm{Al}} & \mathrm{Si}_{3} & \mathrm{O}_{10}\end{array}\right](\mathrm{F}, \mathrm{OH})_{2}\right)$ from the Kovdor phlogopite-vermiculite deposit (Russia) showed that the infrared spectra of phlogopites enable to estimate their properties, including those that determine their quality or technological grade.

It was established [2] that phlogopites of various genetic types contain absorption bands with a maximum of $3700,3660,3620,3550$, and $3400 \mathrm{~cm}^{-1}$ in the region of stretching vibrations of $\mathrm{OH}$ groups. Typomorphic are mainly bands of 3550 and $3400 \mathrm{~cm}^{-1}$. Absorption in the region of $3550 \mathrm{~cm}^{-1}$ is characteristic of multimolecular layers. They are quasi-solid structured entities. The band in the region of $3400 \mathrm{~cm}^{-1}$ corresponds to stretching vibrations of water in the bulk phase, the socalled film water [3].

Consequently, we have revealed the relationship between the intensity of these absorption bands and the physical properties of the phlogopite of the Kovdor phlogopite-vermiculite deposit. So, Fig. 1 clearly demonstrates that the increase in the absorption coefficient at the maximum of the bands of 3550 and $3400 \mathrm{~cm}^{-1}$ leads to the decrease in the hardness of phlogopite, as well as the decrease in the dielectric constant of the mineral. T. Shishelova and co-authors [4] obtained similar data for phlogopites from deposits in Siberia (Russia).

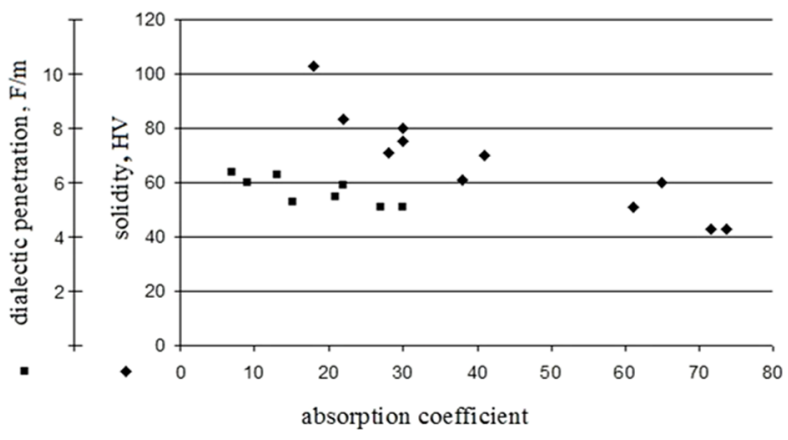

Fig. 1. The relationship between the intensity of the bands of $3550 \mathrm{~cm}^{-1}$ and $3400 \mathrm{~cm}^{-1}$ of the IR spectrum of the phlogopite of the Kovdor deposit and its physical properties.

ICS method acquires the particular importance in assessing the grade of gemstone raw materials. The quality of a gemstone depends on many parameters, among which the most essential is the chemical composition and impurities.

Figure 2 shows the infrared spectra of aquamarines $\left(\mathrm{Be}_{3} \mathrm{Al}_{2} \mathrm{Si}_{6} \mathrm{O}_{18}\right)$ of various grades. As can be seen from the above IR spectra, the region of stretching vibrations of $\mathrm{OH}$ groups of aquamarine depends on the grade of the raw material. Class 1 aquamarine has almost no absorption bands in the region of stretching vibrations of $\mathrm{OH}$ groups. As for class 2 aquamarines, we observe absorption in the region of $\sim 3640,3580 \mathrm{~cm}^{-1}$. Class 3 aquamarines have a wide absorption band with a maximum frequency of $3400 \mathrm{~cm}^{-1}$, which is characteristic of free water. This is clearly expressed in the spectra of low grade aquamarine and is associated with the presence of defective sites where free and surface water is adsorbed. The presence of defective places affects the quality of the mineral. The same regularity is also characteristic of the region of deformation vibrations $\mathrm{OH}\left(v=1620 \mathrm{~cm}^{-1}\right)$ [5].

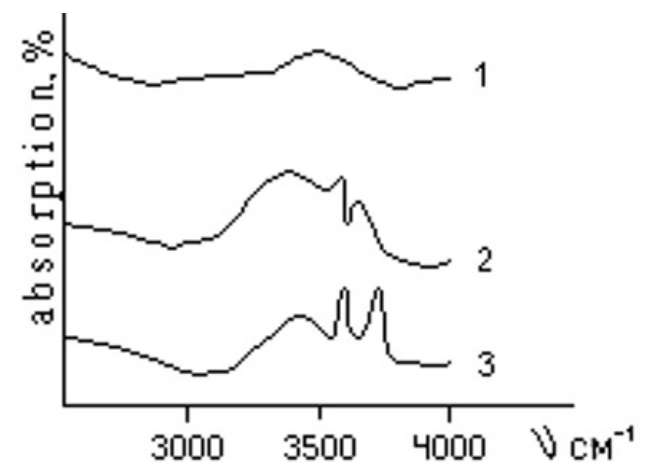

Fig. 2. The infrared spectra of aquamarines $\left(\mathrm{Be}_{3} \mathrm{Al}_{2} \mathrm{Si}_{6} \mathrm{O}_{18}\right)$ of various grades [4]). 
The revealed relationships allow us to provide an operational analysis of the grade of phlogopite raw materials. The operational analysis can be performed both on the basis of geological and technological testing and mapping of deposits, and as a result of selective express analysis in the process stream.

The selection of grades of mineral raw materials is often determined by its phase composition. For example, the possibility of using baddeleyite $\left(\mathrm{ZrO}_{2}\right)$ for the production of glazes is determined, first of all, by the concentration of phosphorus impurities. With its increased content, the glaze becomes dull, which reduces the quality of colored ceramic tiles. The presence of phosphorus in the baddeleyite concentrate of the Kovdor baddeleyite-apatite-magnetite deposit is determined by the presence of micro impurities of apatite $\left(\mathrm{Ca}_{5}\left[\mathrm{PO}_{4}\right]_{3}(\mathrm{~F}, \mathrm{Cl}, \mathrm{OH})\right)$ in it. The content of $\mathrm{P}_{2} \mathrm{O}_{5}$ in the concentrate ranges from 0.05 to $0.93 \%$.

Apatite in baddeleyite concentrate is traced by the presence of information absorption bands in the regions of 640 and $670 \mathrm{~cm}^{-1}$ in the infrared spectrum of baddeleyite. They are responsible for the librational vibrations of the hydroxyl group of apatite. Figure 3 shows a histogram of the distribution of the intensities of the $670 \mathrm{~cm}^{-1}$ band in the spectra of 56 samples of baddeleyite monofractions. The whole sample is clearly divided into two groups. The right maximum corresponds to samples with a high content of apatite micro impurities $\left(\mathrm{P}_{2} \mathrm{O}_{5}\right.$ content exceeds $\left.0.54 \%\right)$ which belong to the grade of substandard baddeleyite confined mainly to the zones of superimposed apatitization of ores of apatite-forsterite-magnetite composition. The left one corresponds to the samples with minimum apatite content suitable as a raw material for the production of glazes.

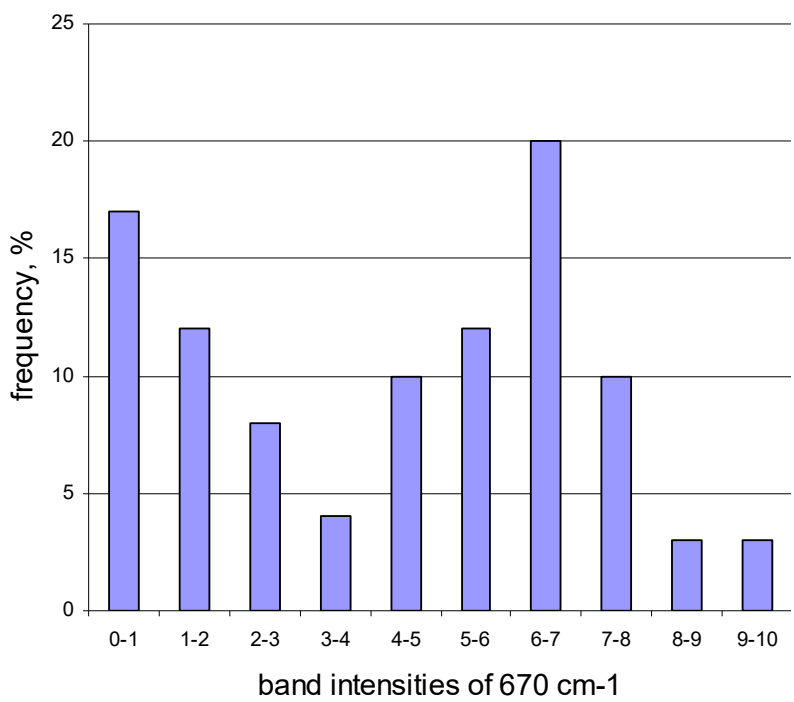

Fig. 3. Histogram of the distribution of quantities band intensities of $670 \mathrm{~cm}^{-1}$ in the spectra of mono-baddeleyite fractions of the Kovdor field.

\subsection{Analysis of the mineral behavior in the process with prediction of their technological properties}

For the efficient processing of mineral raw materials, it is extremely important to study the behavior of the entire complex of minerals (composing ores) at the technological stages of processing, such as crushing, grinding, separation, etc. Real minerals behave differently in technological redistribution because of defective structures, the presence of numerous impurities and inclusions. The task of researchers to control all these aspects, making recommendations for improving the processes of enrichment using a wide range of physical and chemical methods for the analysis of minerals and ores. So, it becomes possible to solve the problem of leading forecasting of technological indicators of ore processing.

For example, the crystal-chemical features of magnetite data obtained through IR spectroscopy are of fundamental importance for solving various problems of the magnetite ores enrichment. First of all, it makes possible to obtain data on assessing the balance of redistribution of useful and harmful elements-impurities in magnetite $\left(\mathrm{FeFe}_{2} \mathrm{O}_{4}\right)$ upon receipt of iron ore concentrate [6], revealing the form of their occurrence.

For example, the infrared spectra of magnetites of the Gusevogorsky deposit are characterized by a similar texture type of mineralization (medium disseminated ores), but significantly different technological enrichment indicators. A shift of the $v_{3}$ band to the lowfrequency region $564 \rightarrow 545 \mathrm{~cm}^{-1}$ is noted (Fig. 4). The position of this band depends on the composition of the mineral and varies over a wide range from $526 \mathrm{~cm}^{-1}$ for hematite, which can be fixed as a product of magnetite oxidation, up to $575 \mathrm{~cm}^{-1}$ for stoichiometric magnetite [7]. IR spectroscopy unambiguously indicates an increase in the internal heterogeneity of Gusevogorsk magnetites. Particularly, the manifestation of isomorphic substitutions of $\mathrm{Fe}^{+3}$ for $\mathrm{Ti}^{+4}$ and the decomposition structures of magnetite-spinel, magnetite-ulvospinel solid solutions reduce the iron content in magnetite concentrate by more than $2 \%$.

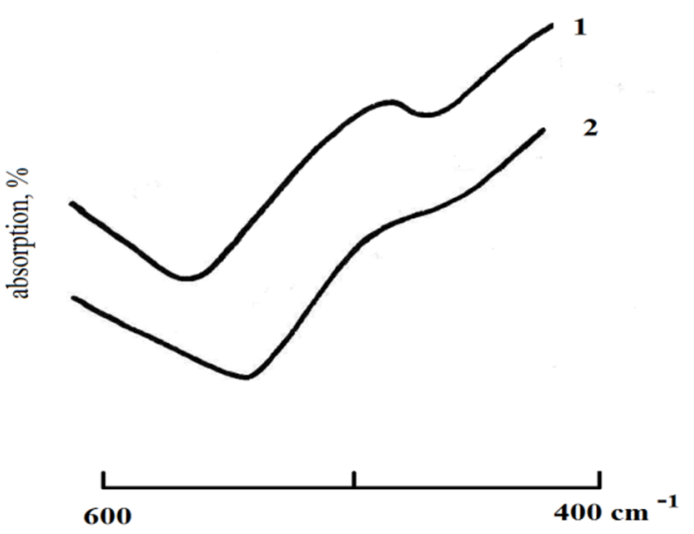

Fig. 4. The change in the position of the $v_{3}$ band in the IR spectra of magnetite of the Kachkanarsky deposit with increasing internal heterogeneity of the mineral $(1 \rightarrow 2)$. 
The infrared spectra of magnetite also make it possible to determine the contrast of the properties of magnetic separation of a mineral, taking into account the peculiarities of its crystal chemistry. Figure 5 shows the relationship between the position of the $v_{3}$ band and the value of the coercive force (Hc) of specially selected magnetite samples from low-iron ores of the Kovdor deposit. The coercive force is one of the most important magnetic characteristics of the mineral which reflects the rigidity of the ferrimagnetic material, and its anisotropy and defective structure as a result. The value of the coercive force increases sharply with the violation of the uniformity of magnetite [6]. The presence of a clear inverse relationship between $v_{3}$ and $\mathrm{Hc}$ of magnetite samples corresponds with these data. We note that the value of the coercive force of the mineral significantly affects the course of magnetic separation. With its increase, flocculation of crushed particles increases with the involvement of non-metallic minerals in the magnetic concentrate [7].

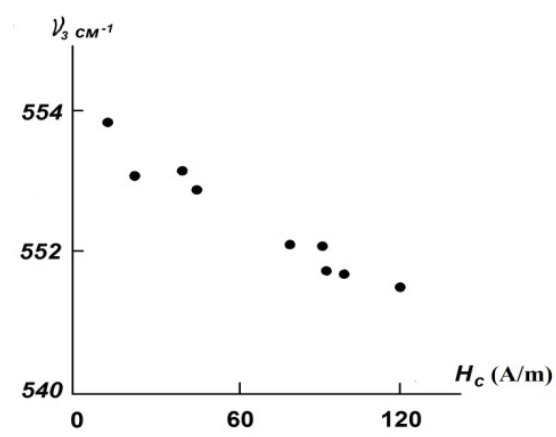

Fig. 5. Dependence of the position of the $v_{3}$ band in the IR spectra on the value of the coercive force Hc of Kovdor magnetite samples.

The most high-temperature iron ore deposits are characterized by heterogeneity of the structure and heterogeneous composition of magnetite. The crystalchemical features of the mineral are the main geological and mineralogical factor determining the ore dressability. Respectively, it he is reasonable to select technological varieties of ores by using the crystalchemical features of magnetite. The use of IR spectroscopy here is very effective. It becomes possible to construct geological and technological maps of deposits when mapping the typomorphic feat ures of the infrared absorption spectra of magnetite.

In the infrared spectra of the apatite of the Kovdor deposit, there are two absorption bands that most informatively characterize and objectively fix the crystal chemical heterogeneity of the mineral. They are: a single absorption band in the region of $870-886 \mathrm{~cm}^{-1}$, corresponding to the non-degenerate vibration $v_{2}$ of the anion $\left(\mathrm{CO}_{3}\right)^{2-}$, and also part of the asymmetric deformation $v_{4}$ vibrations of the $\left(\mathrm{PO}_{4}\right)^{3-}$ ion. There is a clear inverse relationship between the intensity of these bands, which obviously indicates an isomorphic mechanism for the entry of the $\mathrm{CO}_{3}$ group into the position of the phosphate tetrahedron [7].

The result of this is the established inverse relationship between the intensity of the absorption band of the $\left(\mathrm{CO}_{3}\right)^{2-}$ group on the IR spectra of apatite in the region of $870 \mathrm{~cm}^{-1}$ and the $\mathrm{P}_{2} \mathrm{O}_{5}$ content in apatite concentrate (Fig. 6). This is caused by an increase in the structure of the mineral deficit of active $\mathrm{Ca}_{2}$ ions, which directly interact with the flotation reagent, when phosphorus is replaced by carbon. As a result, the flotation activity of apatite decreases sharply and carbonate material is involved in the concentrate. There is also a decrease in the weight fraction of $\mathrm{P}_{2} \mathrm{O}_{5}$ in the composition of the mineral.

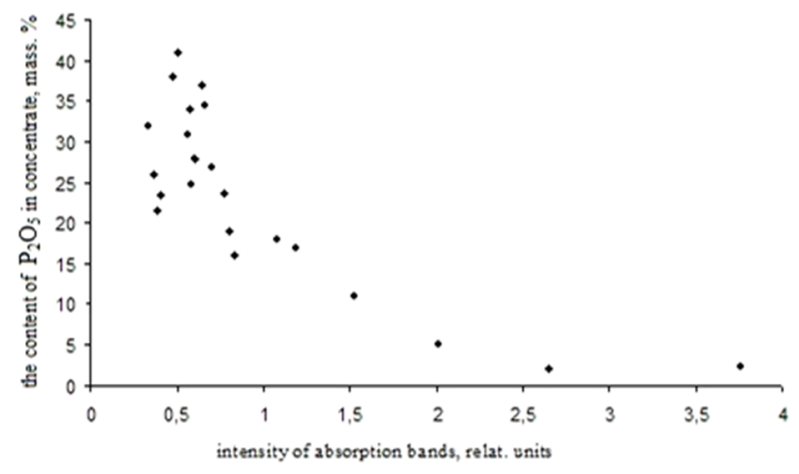

Fig. 6. The relationship between the intensity of the absorption band of the group $\left(\mathrm{CO}_{3}\right)^{2-}$ in the IR spectra of apatite of the Kovdor deposit in the region of $870 \mathrm{~cm}^{-1}$ and the content of $\mathrm{P}_{2} \mathrm{O}_{5}$ in the apatite concentrate.

Thus, the IR spectra of the apatite of the Kovdor deposit make it possible to evaluate the contrast of the flotation properties of the mineral in ores of carbonatite complexes, and as a result, to predict the technological properties of ores. The described method for predicting the technological properties of apatite ores of carbonatite complexes is protected by copyright [9].

IR spectroscopy is widely used to study surface phenomena when fixing flotation reagents to minerals $[10,11,19]$. A study of the chemistry of reactions during the adsorption of anionic and cationic collectors makes it possible to conclude the place and nature of the fixation of the reagents, as well as to trace the change in surface properties when exposed to regulators.

\subsection{Analysis of changes in the structure and properties of minerals in technological processes}

The technological properties acquired by minerals under various influences should be considered as a dynamic process of superposition of constitutional (standard) and secondary (induced) properties [13]. The significant changes in various natural mineral properties (morphology, granulometry, constitution (crystal chemistry), etc.) begin as soon as it undergoes explosion (during mining), crushing, grinding (during processing) and any types of separation. B. I. Pirogov [6] states it is here that the influence of technogenesis due to external energy effects (mechanical, temperature, chemical, etc.) affects the change in the constitution of the mineral. Infrared spectroscopy allows to analyze effectively the dynamics of these changes. 
Thus, for example, significant changes are observed in the IR spectra of the initial and ground Pechenga diopside $\left(\mathrm{CaMg}\left(\mathrm{Si}_{2} \mathrm{O}_{6}\right)\right)$. They are related to the appearance of new bands in the samples of the crushed mineral in the region of 3400 and $1640 \mathrm{~cm}^{-1}$, which correspond to vibrations of the $\mathrm{OH}$ group. This indicates that during grinding there is a noticeable hydration of the surface of the mineral grains due to the presence of atmospheric one. In addition, the appearance of a double peak in the region of $1500 \mathrm{~cm}^{-1}$ is observed. The position of this peak corresponds to the absorption band of the carbonate group and is due to the absorption of carbon dioxide by mechanically chemically activated diopside [13].

The technological cycle of the "life" of the mineral continues after the processing of mineral raw materials. Thus, studies by M. S. Khokhuli with co-authors [13] find that in the IR spectra of the phlogopite of the Kovdor phlogopite-vermiculite deposit, the intensity of bands caused by vibrations of free water molecules and hydroxyl groups $\left(3700-1600 \mathrm{~cm}^{-1}\right)$ increases in samples subjected to long-term storage in the underground conditions of the mine (more than 20 years). Consequently, it is proved that the structure of phlogopite changes with the formation of up to $5 \%$ vermiculite layers in it during the storage of phlogopite crystals. The changes caused by phlogopites hydration and partial decationation of sections of its crystals ultimately affect the significant deterioration of their technical properties.

The deformations of the minerals structure that occur under the influence of physical influences (temperature, radiation, ultrasound, electro-kinetic, etc.) are the most significant and interesting for technological purposes. Such deformations allow the directional transformation of their technological properties. Infrared spectroscopy provides the choice of the optimal modification method with a targeted change in the contrast of the separated minerals. This allows ultimately optimizing the technological scheme of processing of raw materials.

Figure 7 shows the results of an experiment we conducted when studying the temperature transformations of goethite of the Skelevat iron ore deposit (Kryvyi Rih). We recorded a series of intense absorption bands characterized by the stretching and deformation vibrations of $\mathrm{OH}$ groups in the infrared spectrum of goethite in the region of $3600-3200 \mathrm{~cm}^{-1}$ at room temperature [14]. It is observed a change in the spectral pattern in this region with a gradual heating of the mineral. To a temperature of $180{ }^{\circ} \mathrm{C}$ is a gradual decrease in the intensity of the absorption bands of hydroxyl groups. A sharp decrease in the intensity of this band is observed at $190{ }^{\circ} \mathrm{C}$ in the spectrum of the mineral, which again changes into its monotonic decrease at $200^{\circ} \mathrm{C}$ up to $600^{\circ} \mathrm{C}$.

Such a change in the spectrum is associated with a gradual disruption of the $\mathrm{FeO}-\mathrm{O}$ bond with an increase in temperature to $190{ }^{\circ} \mathrm{C}$ and a redistribution of the energies of all the bonds of the system. In the range of $190-200{ }^{\circ} \mathrm{C}$, a hematite structure begins to form along with goethite. A further increase in temperature (up to $600^{\circ} \mathrm{C}$ ) leads to the gradual removal of hydroxyl groups and the formation of a stable hematite structure.

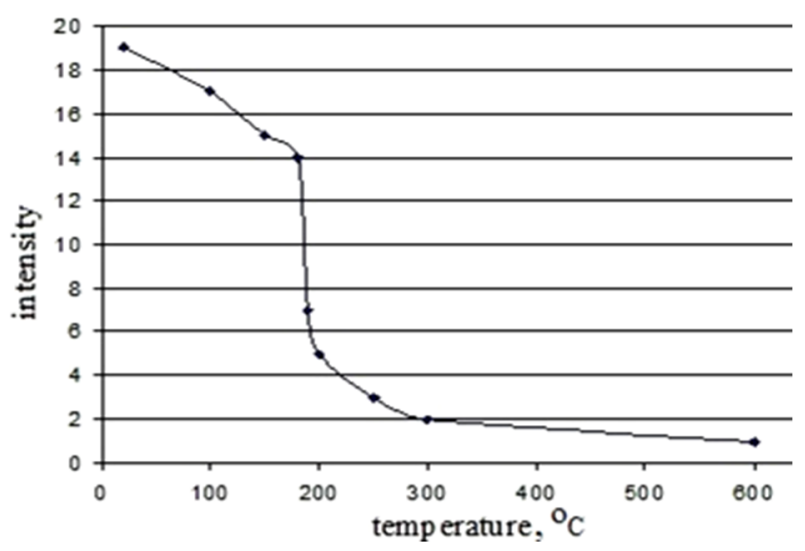

Fig. 7. Changes in the intensity of absorption bands in the region of $3600-3200 \mathrm{~cm}^{-1}$ in the IR spectra of goethite of the Skelevat iron ore deposit under temperature exposure.

A group of researchers led by V. Chanturia [16] studied the change in the composition of surface layers and the chemical state of atoms on the surface of galena $(\mathrm{PbS})$ as a result of exposure to high-voltage nanosecond electromagnetic pulses. It was established that after an energetic effect on the mineral, an integrated change in the band area is observed in the range of $1000-1400 \mathrm{~cm}^{-1}$ of the IR spectrum. This change corresponds to the absorption band of the deformation vibrations of the $\mathrm{H}-\mathrm{O}-\mathrm{H}$ bond, which indicates a change in the hydration of the surface of galena particles. This creates favorable conditions for adsorption of the anion collector and contributes to an increase in the flotation activity of galena.

\subsection{Operational analysis of minerals at various stages of technological processing}

The effective management of modern mining and processing operations is largely determined by the efficiency and reliability of information on the composition and properties of processed products at various technological cycles. So, much attention is paid today to the development of operational control methods both at the stage of extraction and processing of ores. This is especially true considering the fact that at the end of the 20th century models of portable infrared spectrometers, simple and affordable, with low cost, were developed and are widely available. Consequently, today there are already examples of the effective industrial use of IR analyzers $[17,18]$.

The IR spectrum of any substance (the position of the absorption bands, their intensity, width and shape) is individual, and can be used to identify this substance. The infrared spectrum of the mineral mixture is the sum of the spectra of the components of the mixture, and the intensity of the absorption bands in the spectrum of each component is proportional to its content in the mixture [15].

Thus, the principle of additivity of IR spectra makes it possible to develop an inexpensive express analysis on the 
basis of this method in the cycle of geological and technological control of mining and processing enterprises.

A number of examples of this application of infrared spectroscopy are given in the modern literature [26]. The main focus of these works is the development of methods for increasing the accuracy of analysis. So a group of researchers led by R. A. Skochilova proved that in this case the baseline method traditionally used for the quantitative analysis of minerals by their IR spectra is ineffective [19].

This is due to the fact that the spectra of matrices (batch, core and other products of various cycles of technological conversion) can vary within significant limits, and to a greater or lesser extent overlap the analytical bands of the analyzed mineral. The authors suggest using mathematical-statistical information processing and, in particular, the factor analysis method. This approach allows to find individual spectra and concentrations up to an arbitrary factor from a set of experimental spectra of a mixture with different contents of components. The advantage of this approach is that the IR spectra of several mixtures are analyzed simultaneously in a wide spectral range, and baseline measurements are not required to extract quantitative information.

\section{Conclusion}

Infrared spectroscopy is a highly effective method for the analysis of minerals, rocks and ores, capable of solving a whole range of problems when choosing innovative solutions for the technological processing of various types of mineral raw materials. The main areas of application of IR spectroscopy are: assessment of grade (quality) of mineral raw materials; analysis of the behavior of minerals in the technological process with prediction of their technological properties; analysis of changes in the structure and properties of minerals in technological processes; operational analysis of mineral substances at various stages of technological processing. The article provides numerous examples of this use of the IR spectroscopy method. The information capabilities of the infrared spectroscopy method are significantly expanded when it is used in combination with other physical and chemical methods of analysis: X-ray diffraction, thermal, electron paramagnetic resonance, scanning microscopy, etc.

The direction of further research is the application of the infrared spectroscopy method in the development of new technologies for the extraction of useful components based on nanotechnologies.

\section{References}

1. B. Pirogov, GMV. 1, 5-17 (2008)

2. V. Farmer JMM. 31, 241-329 (1958)

3. M. Mecik, T. Shishelova, V. Liopo, JAS. 3, 464465 (1966)
4. T. Shishelova, A. Kolodeznikova, V. Shulga, FI. 2 (15), 3294-3298 (2015)

5. E. Giesekke, JMP 11, 9-56 (1983)

6. B. Pirogov, G. Porotov, I. Holoshin, V. Tarasenko, Tehnologicheskaya mineralogiya zheleznyh rud (Technological Mineralogy of Iron Ores). (Nauka, Leningrad, 1982)

7. B. Pirogov, A. Trunin, I. Holoshin, GMV. 1, 78-87 (2001)

8. A. Moiseenko, L. Orlov, G. Bogatkin, V. Strelchenko, V. Komandrovskij, I. Egorova, MNTO PRIB. 11 (41), 21-27 (2003)

9. B. Pirogov, I. Holoshin, A. Trunin, A.s. 17879 SSSR, G01V9/00/(SSSR). No. 1783461, 23.12.1992

10. Yu. Batura, M. Uglovskaya, OBRUD 5, 24-25 (2005)

11. J. Miller, J. Kellar, W. Cross, in Adv Coal Miner Process Using Flotation Proc Eng Found Conf., (Littleton, 1998), pp. 33-44

12. V. Revnivcev, G. Dolivo-Dobrovolskaya, P. Vladimirov, Tehnologicheskaya mineralogiya oblomochnyh malyh chastic (Technological mineralogy of clastic small particles). (Nauka, SPb, 1993)

13. M. Hohulya, M. Maslova, L. Gerasimova, GIAB 2, 180-192 (2013)

14. A. Remizov, D. Kamalova, R. Skochilov, I. Suvorova, N. Batyrshin, Kh.E. Kharlampidi, VKY 700, 73-79, (2004)

15. I. Plyusnina, Infrakrasnye spektry mineralov (Infrared Spectra of Minerals). (Nauka, Moscow, 1977)

16. V. Chanturiya, V. Makarov, A. Kalinkin et al, CM 10, 80-85 (2000)

17. V. Komandrovskij, A. Moiseenko, ATSNP. 8, 2528 (2012)

18. R. Skochilov, A. Fshman, A. Ivanov, VKY 5, 135142 (2011)

19. R. Clark, T. Roush, Reflectance spectroscopy: quantitative analysis techniques for remote sensing applications. JGR (1984). doi:10.1029/JB089iB07p06329

20. A. Smith, Pricladnaya IK spektroskopiya (Applied IR Spectroscopy). (Mir, Moscow, 1982), p. 328

21. V. Chanturiya, Yu. Brylyakov, E. Kopoprulina, M. Ryazanceva, FHPRPI (SO RAN) 4, 136-149 (2014)

22. V. Chanturiya, I. Bunin, M. Ryazanceva, I. Habarova, E. Koporulina, N. Anashkina, Aktivaciya poverhnosti i napravlennoe izmenenie fizikohimicheskih i tehnologicheskih svojstv galenita pri vozdejstvii nanosekundnyh elektromagnitnyh impulsov (Surface activation and directional change in the physicochemical and technological properties of galena when exposed to nanosecond electromagnetic pulses). FHPRPI 3, 154-169 (2014) 
23. E. Ozhogina, A. Rogozhin, Prognoznaya ocenka tehnologicheskih svojstv poleznyh iskopaemyh metodami prikladnoj mineralogii (Predictive evaluation of technological properties of mineral resources by applied mineralogy methods), in Seminar on Technological Mineralogy Moscow, ed. by V. Shchiptsov, April 9-11, 2012 (Petrozavodsk, 2013), pp. 46-49

24. A. Guatame-García, M. Buxton, F. Deon, C. Lievens, C. Hecker, MEMR 11(2), 420-421 (2018)

25. I. Plaksin, V. Solnyshkin, Infrakrasnaya spektroskopiya poverhnostnyh sloev reagentov na mineralah (Infrared spectroscopy of surface layers of reagents on minerals). (Nauka, Moscow, 1966)

26. R.L. Frost, Hydroxyl deformation in kaolins. Clays and Clay Minerals 46(3), 280-289 (1998). doi:10.1346/ccmn.1998.0460307

27. R.L. Frost, É. Makó, J. Kristóf, J.T. Kloprogge, Modification of kaolinite surfaces through mechanochemical treatment - a mid-IR and near-IR spectroscopic study, Spectrochimica Acta Part A: Molecular and Biomolecular Spectroscopy 58(13), 2849-2859 (2002). doi:10.1016/S13861425(02)00033-1

28. R.L. Frost, A.M. Vassallo, The dehydroxylation of the kaolinite clay minerals using infrared emission spectroscopy. Clays and Clay Minerals 44(5), 635651 (1996). doi:10.1346/CCMN.1996.0440506

29. R. Lima, P. Brandao, A. Peres, Min. Engin. 18, 267273 (2005)

30. E. Malinowski, Factor analysis in chemistry (Wiley, Hoboken, 2002), p. 432

31. Xiu Liancun, Zheng Zhizhong, Chen Chunxia, Gao Yang, in International Conference on Progress in Informatics and Computing 2017 